\title{
Burden of Road Traffic Injuries in Tanzania: One-Year Prospective Study of Consecutive Patients in 13 Multilevel Health Facilities
}

\author{
Hendry R. Sawe ${ }^{1 D},{ }^{1,2}$ Sveta Milusheva, ${ }^{3}$ Kevin Croke, ${ }^{3,4}$ Saahil Karpe, ${ }^{5}$ \\ Meyhar Mohammed, ${ }^{3}$ and Juma A. Mfinanga ${ }^{2}$ \\ ${ }^{1}$ Department of Emergency Medicine, Muhimbili University of Health and Allied Sciences, Dar es Salaam, Tanzania \\ ${ }^{2}$ Department of Emergency Medicine, Muhimbili National Hospital, Dar es Salaam, Tanzania \\ ${ }^{3}$ Development Impact Evaluation Group, World Bank, Washington, DC, USA \\ ${ }^{4}$ Harvard T. H. Chan School of Public Health, Boston, MA, USA \\ ${ }^{5}$ Lyft, San Francisco, CA, USA \\ Correspondence should be addressed to Hendry R. Sawe; hendry_sawe@yahoo.com
}

Received 23 September 2021; Revised 14 October 2021; Accepted 27 October 2021; Published 10 November 2021

Academic Editor: Piergiorgio Fedeli

Copyright (c) 2021 Hendry R. Sawe et al. This is an open access article distributed under the Creative Commons Attribution License, which permits unrestricted use, distribution, and reproduction in any medium, provided the original work is properly cited.

\begin{abstract}
Background. Road traffic injuries (RTIs) pose a severe public health crisis in Sub-Saharan Africa (SSA) and specifically in Tanzania, where the mortality due to RTIs is nearly double the global rate. There is a paucity of RTI data in Tanzania to inform evidencebased interventions to reduce the incidence and improve care outcomes. A trauma registry was implemented at 13 health facilities of diverse administrative levels in Tanzania. In this study, we characterize the burden of RTIs seen at these health facilities. Methods. This was a one-year prospective descriptive study utilizing trauma registry data from 13 multilevel health facilities in Tanzania from 1 October 2019 to 30 September 2020. We provide descriptive statistics on patient demographics; location; share of injury; nature, type, and circumstances of RTI; injury severity; disposition; and outcomes. Results. Among 18,553 trauma patients seen in 13 health facilities, 7,416 (40\%) had RTIs. The overall median age was 28 years (IQR 22-38 years), and 79.3\% were male. Most road traffic crashes (RTC) occurred in urban settings (68.7\%), involving motorcycles (68.3\%). Motorcyclists (32.9\%) were the most affected road users; only $37 \%$ of motorcyclists wore helmets at the time of the crash. The majority (88.2\%) of patients arrived directly from the site, and $49.0 \%$ used motorized (two- or three-) wheelers to travel to the health facility. Patients were more likely to be admitted to the ward, taken to operating theatre, died at emergency unit (EU), or referred versus being discharged if they had intracranial injuries $(27.8 \%$ vs. $3.7 \%$; $p<0.0001)$, fracture of the lower leg $(18.9 \%$ vs. $6.4 \%$; $p<0.0001)$, or femur fracture $(12.9 \%$ vs. $0.4 \%$; $p<0.0001)$. Overall, $36.1 \%$ of patients were admitted, $10.6 \%$ transferred to other facilities, and mortality was $2 \%$. Conclusions. RTCs are the main cause of trauma in this setting, affecting mostly working-age males. These RTCs result in severe injuries requiring hospital admission or referral for almost half of the victims. Motorcyclists are the most affected group, in alignment with prior studies. These findings demonstrate the burden of RTCs as a public health concern in Tanzania and the need for targeted interventions with a focus on motorcyclists.
\end{abstract}

\section{Background}

Road traffic injuries (RTIs) contribute significantly to the global burden of diseases posing a particularly severe public health crisis in Sub-Saharan Africa (SSA) and specifically in Tanzania, where the mortality due to RTIs is nearly double the global rate [1]. Unfortunately, the latest multicountry survey reveals that very few countries in the SSA region have developed systematic emergency medical services (EMS) and prehospital care systems at scale; this has the potential to affect the outcomes for road crash victims [2].

In Tanzania, RTIs contribute significantly to the burden of disease, with significant morbidity and mortality among accident victims [3-5]. Like most low- and middle-income countries (LMICs), Tanzania lacks formal trauma care systems that further contribute to its challenges in 
addressing the large burden of injuries [6]. Furthermore, recent studies have suggested that healthcare facilities in this context are not adequately equipped to meet trauma care needs and face major gaps in coordinated emergency response [7]. Despite the high rates of RTI-related deaths in Tanzania [8], there is a gap in detailed trauma data that could inform policymakers about factors in emergency care that affects RTIs. This gap provides an opportunity to improve postinjury care and outcomes for RTI patients, through the implementation of EMS that incorporates reliable trauma and crash data. One of the key impediments identified for the development of robust EMS systems is the lack of datadriven information management systems that record longitudinal patient-level trauma data to provide region-specific evidence to improve outcomes on postcrash response [9]. In an effort to improve postcrash care and reduce fatalities from RTIs, the Government of Tanzania supported by the World Bank planned to implement a pilot EMS on the busy A7 highway connecting the North-South corridor of Tanzania [10]. In order to understand the health impacts of this pilot EMS in Tanzania, we implemented a multisite prospective trauma registry (TR) data collection at emergency units (EUs) of 13 multilevel health facilities that include the diverse scale of the administrative structure of Tanzania's public health infrastructure. In this manuscript, we characterize the burden of RTIs in these facilities, as a crucial step of setting a baseline for the future impact evaluation of EMS implementation in Tanzania and other similar settings in LMICs.

\section{Methods}

2.1. Study Design and Population. This was a one-year prospective descriptive study of all RTI patients presenting to 13 multilevel health facilities in Tanzania from 1 October 2019 to 30 September 2020.

2.2. Study Setting. The United Republic of Tanzania is a lower-middle-income country with a population of 60 million people $[11,12]$. The public health system is organized in a pyramidal structure from the lowest level of the primary dispensary, followed by the health center, district hospital, regional hospital, national, and consultant hospitals [13]. There is no formal trauma care system and no formal prehospital system.

In an effort to mitigate the burden of RTIs, the Government of Tanzania, supported by the World Bank, planned a pilot implementation of EMS along the A7 highway that connects the north and south of Tanzania. This pilot EMS implementation included the creation of an ambulance dispatch center, activation of an emergency access telephone number, training community first responders, paramedics, fire safety personnel and drivers, procuring and equipping ambulances, and renovation of emergency units (EUs) in 6 health facilities located within $2 \mathrm{~km}$ of the A7 highway (from Dar es Salaam to Morogoro) that included 2 regional hospitals (Tumbi and Morogoro), 3 health centers (Kimara, Chalinze, and Mikumi), and 1 dispensary (Fulwe).
In order to understand the impact of this pilot EMS implementation, we set up a trauma registry to enroll all injured patients at EUs of 13 public health facilities (Figure 1) that include all 6 health facilities involved in the pilot EMS implementation and 7 additional (comparison group) not part of the EMS implementation. The 7 additional (comparison group) facilities included 2 regional hospitals (Dodoma and Mawenzi), 3 district hospitals (Same, Korogwe, and Mvomero), and 2 health centers (Mkata and Gairo), all of which were located on a different though comparable highway.

2.3. Data Source. In EUs of each of the 13 health facilities, we implemented a paper-based standardized trauma form that had previously been developed and piloted at 5 different regional hospitals in Tanzania [14], prior to the launch of this project. This standardized trauma form was adopted and modified from the World Health Organization (WHO) standardized trauma form [15]. Prior to this implementation, we further modified and repiloted the form to ensure additional RTI variables could be collected. The trauma form was used for clinical documentation, and it had a carbonless copy to allow the duplication of information to be used for abstracting data into a digital platform hosted through an online data capture software Research Electronic Data Capture (REDCap; ( ) REDCap version 7.2.2, Vanderbilt, Nashville, TN, USA).

In each health facility, injured patients presenting after an RTC were manually recorded into the trauma forms by clinicians and the research assistant (RA). The data from manual trauma forms were entered into the online REDCap system by the RA once the care process had been completed. The principal investigators received copies of the completed trauma forms from each of the sites for verification and data quality validation.

2.4. Personnel Training. In each of the 13 health facilities, we recruited and trained a trauma data coordinator (TDC) and RA who supported the data collection process. TDCs were healthcare providers (clinician or nurse) in the facility, which provided site project oversight and ensured buy-in and compliance. Both TDCs and RAs received dedicated training that focused on an overview of primary trauma care, the context of impact evaluation, and the use of the trauma registry paper form and the REDCap tool using digital tablets.

2.5. Data Analysis. Data from REDCap was exported into the Stata 16 StataCorp, College Station, TX, USA, for analysis. Descriptive statistics are presented as mean and median with corresponding standard deviation and interquartile range as appropriate. The final EU diagnoses were coded using the International Classification of Diseases (ICD) 10, and a chi-square test was used to test the categorical variables. The map of the location of facilities was constructed using a shapefile of the facilities in the QGIS Development Team (2021) Geographic Information System. In order to understand the share of RTC at a district level, we created a heat map using R Studio 2020 (Boston, MA). 


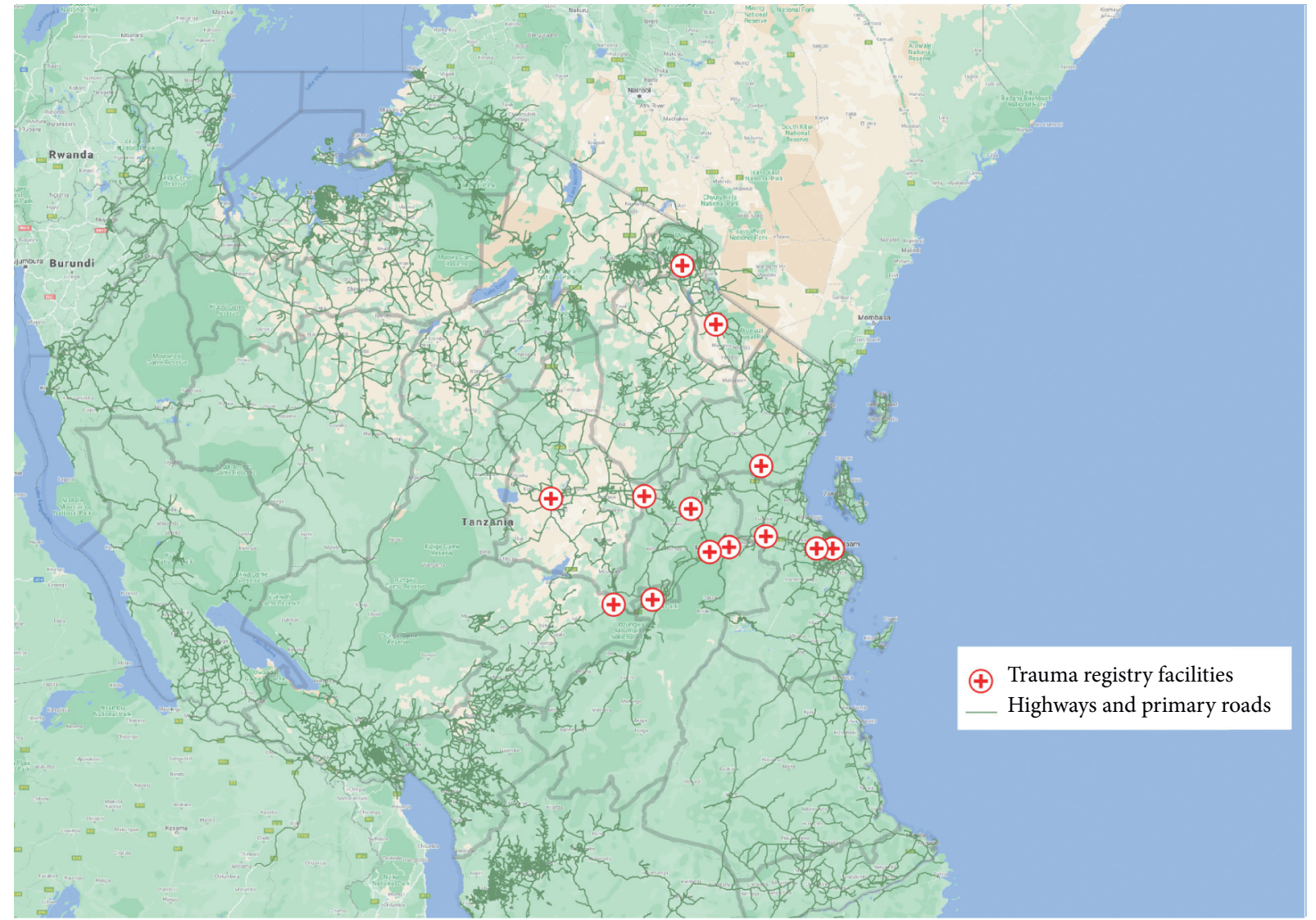

FIgURE 1: Map of Tanzania showing the location of each health facility.

\section{Results}

3.1. Patient Characteristics. A total of 18,553 trauma patients were seen in all health facilities, out of which 7,416 (40\%) had RTIs. Among those who had RTIs, 5,862 (79.3\%) were male, and the overall median age was 28 years (interquartile range $22-38$ years). Petty traders 1,790 (25.3\%), drivers 1,495 (21.1\%), farmers 1,322 (18.7\%), and students $806(11.4 \%)$ were the most common occupations recorded. Most patients 6,455 (88.2\%) presented directly from the scene of the crash, and 3,632 (49\%) used a motorized (two- or three-) wheeler as a mode of arrival to the facility. Only $497(6.7 \%)$ used ambulances to arrive at the facility. In the EU, $94 \%$ of patients were triaged as priority or emergency cases requiring immediate emergency care (Table 1).

3.2. Description of Nature of RTI with Risk Factors for Serious Injuries. Most RTC victims (65.7\%) came from urban settings, as compared to $(60.5 \%)$ of all trauma victims broadly from urban settings. Additionally, of victims who were in a motorized vehicle, over two-thirds were the drivers or passengers of motorcycles (67.9\%). A majority of motorcycle drivers and passengers (62.6\%) were not wearing helmets at the time of the crash, and similarly, among the vehicle occupants, only $17.4 \%$ had seat belt protection at the time of the accident. Motorcyclists and bicyclists accounted for over half (53\%) of the patients involved in RTCs and nonmotorized users (pedestrians and cyclists) accounted for $42.2 \%$ of the patients. Almost half of these nonmotorized users (48\%) were hit by a motorcycle. Alcohol use was missing or reported unknown in $69.4 \%$ of injured patients; alcohol use was reported in $1.2 \%$ of cases. Morning (0600-1159 hours) and evening (1800-2359 hours) rush hours accounted for most of the accidents at $35.6 \%$ and $26.2 \%$, respectively. A plurality of patients $1781(29.8 \%)$ arrived in the EU 1-2 hours after the crash, while only 750 (12.5\%) arrived in less than 30 minutes (Table 2).

3.3. ICD-10 Diagnosis and Final EU Disposition. Multiple superficial injuries (35.6\%) and open wounds (26.6\%) were leading diagnoses, and patients with these diagnoses were more likely to be discharged. Overall, a majority of patients with intracranial injury $977 / 1110$ (88.0\%), femur fracture $453 / 466(97.2 \%)$, and fracture of the lumbar spine and pelvis $41 / 44$ (93.2\%) were admitted to the ward, taken to the operating theatre, died at EU, or referred to other facilities. Patients were more likely to be admitted to the ward, taken to operating theatre, died at EU, or referred to other facilities versus being discharged if they had intracranial injuries (27.8\% vs. $3.7 \% ; p<0.0001)$, fracture of the lower leg $(18.9 \%$ vs. $6.4 \%$; $p<0.0001)$, or femur fracture $(12.9 \%$ vs. $0.4 \%$; $p<0.0001$; Table 3). 
TABLE 1: RTI patient characteristics.

\begin{tabular}{|c|c|}
\hline & $N=7,416$ \\
\hline $\operatorname{Sex}^{\mathrm{n}}$ & $n(\%)$ \\
\hline Male & $5,862(79.3 \%)$ \\
\hline Female & $1,529(20.7 \%)$ \\
\hline \multicolumn{2}{|l|}{ Age } \\
\hline Median (IQR) years & 28 years (IQR: $22-38$ years) \\
\hline Age groups & $n(\%)$ \\
\hline$<5$ years & $146(1.99)$ \\
\hline $5-14$ years & $482(6.5)$ \\
\hline $15-24$ years & $1,922(26.14)$ \\
\hline $25-34$ years & $2,426(32.9)$ \\
\hline $35-44$ years & $1,154(15.6)$ \\
\hline $45-54$ years & $658(8.9)$ \\
\hline $55-64$ years & $308(4.2)$ \\
\hline$>65$ years & $258(3.5)$ \\
\hline \multicolumn{2}{|l|}{ Triage level* } \\
\hline Emergency & $1,736(23.4)$ \\
\hline Priority & $5,234(70.6)$ \\
\hline Queue & $330(4.5)$ \\
\hline \multicolumn{2}{|l|}{ Referral status } \\
\hline Direct from crash site & $6,455(88.2)$ \\
\hline Referred & $867(11.8)$ \\
\hline \multicolumn{2}{|l|}{ Occupation } \\
\hline Petty trader & $1,790(25.3)$ \\
\hline Driver & $1,495(21.1)$ \\
\hline Farmer & $1,322(18.7)$ \\
\hline Student & $806(11.4)$ \\
\hline Manual laborer & $221(3.0)$ \\
\hline Others $^{\rho}$ & $1,451(20.0)$ \\
\hline \multicolumn{2}{|l|}{ Mode of arrival $^{H}$} \\
\hline Motorcycle & $2,347(31.7)$ \\
\hline Car & $1,806(24.5)$ \\
\hline Tricycle & $1,285(17.3)$ \\
\hline Minibus & $781(10.5)$ \\
\hline Ambulance & $497(6.7)$ \\
\hline Walk-in & $323(4.4)$ \\
\hline Bus & $10(0.13)$ \\
\hline Bicycle & $16(0.2)$ \\
\hline Others & $293(3.95)$ \\
\hline
\end{tabular}

*116 (1.6\%) observations are missing triage status, ${ }_{2} 25(0.3 \%)$ are missing gender, and ${ }^{\mathrm{H}_{56}}(0.8 \%)$ missing mode of arrival to EU. ${ }^{p}$ includes office worker, military, mining, craftsman, health worker, unemployed, retired individuals, housewife, unknown, and other unspecified.

3.4. Final EU Disposition by Patient's Role. Overall, 3540 (47\%) patients were either admitted or referred to higher-level health facilities with more resources and personnel. Pedestrians have the lowest rate of being discharged home 669 (42.2\%), signaling a higher severity of injuries suffered, while 1,214 (51.2\%) of motorcyclists were discharged home from the EU. Overall, 144 (1.9\%) of RTC victims died (including 73 (0.98\%) deaths in the EU and $71(0.96 \%)$ in transit or on the scene of the crash). Among those who died, the pedestrian 31/144 (21.5\%) accounted for the highest proportion, followed by cyclists, which accounted for 30/144 (20.8\%; Table 4).

3.5. Road Traffic Crash Share by District. There is geographic variation in the burden of road traffic crashes across the districts surrounding the health facilities. We found that
Temeke (81\%), Kigamboni (77\%), Ilala (82\%), Kilombero (75\%), Kinondoni (70\%), Siha (57\%), Dodoma (57\%), Rombo (54\%), Same (53.08\%), Kibaha (50\%), and Kisarawe (63\%) have more than half of their recorded trauma as RTC (Figure 2). It should be noted that for some of these districts, the denominator (total number of trauma cases) could be small, especially those districts further away from health facilities in which data was recorded.

\section{Discussion}

In this prospective registry-based study of 13 multilevel health facilities in Tanzania, we found a substantial burden of injuries resulting from RTCs, with the majority of patients having injuries serious enough to require admission or transfer to a higher level of trauma care. This multisite implementation of a trauma registry and diverse nature of health facilities ranging from dispensary to regional level hospital provides a broader picture of the burden of RTIs received in health facilities, compared to previously published literature.

Similar to previously published literature in LMICs $[3,5,16]$, motorcyclists accounted for the largest proportion of victims of injuries presenting to these facilities, with the majority of vehicles involved in crashes being a motorcycle. We found a very low threshold of wearing protective equipment (helmets and seat belts) for safety among all vehicle occupants at the time of the crash. Given the amount of evidence supporting the impact of protective equipment in RTC [17], these findings provide a great opportunity for targeted road safety policy and regulation interventions that have a substantial and instant impact on the outcome of injuries resulting from RTCs [18].

Bicyclists and pedestrians each make up around 20\% of road crash victims, which is in line with other LMIC studies [19]. Not surprisingly, a higher share of pedestrians experience potentially more severe trauma as compared to other road users. Limitations on road infrastructure such as lack of dedicated walk and bicycle lanes, as well as failure to observe road safety regulations, might be attributed to this high incidence. Improvement in road infrastructure and instituting appropriate legal guidelines has been shown to reduce the incidence of RTCs in most high-income countries (HICs) [20]; hence, similar interventions in Tanzania will likely have an impact on RTCs in these groups.

Interestingly, we found a peak of RTC in the day and evening time that corresponds to the peak traffic times in Tanzania, and the majority of cases occurring at night were severe as compared to daytime cases. Improvement of road infrastructure and targeted road surveillance by law enforcing agencies during peak hours to enforce safe driving is likely to have an impact in reducing the incidence of RTCs in these settings. Rapid urbanization and motorization have been associated with increased incidents of RTC in most LMICs [21]; likewise, in our study, over two-thirds of RTCs were reported to have occurred in urban settings. Over half of victims coming to these facilities were aged between 15 and 34 years of age, with the majority being male, working as petty traders or professional drivers, findings in concurrence with global data on RTC [1]. 
TABle 2: Description of nature of RTI with risk factors for serious injuries.

\begin{tabular}{|c|c|c|c|}
\hline & $\begin{array}{l}\text { Overall } \\
N(\%)\end{array}$ & $\begin{array}{c}\text { Nondischarged* } \\
n(\%)\end{array}$ & $\begin{array}{c}\text { Percentage of nondischarged }^{\Phi} \\
n / N(\%)\end{array}$ \\
\hline Vehicle involved in $\mathrm{RTC}^{\rho}$ & $N=3,480$ & $n=1,647$ & \\
\hline Motorcycle & 2, $375(67.91)$ & $1,151(69.62)$ & $1,151 / 2,375(48.46)$ \\
\hline Bus/minibus & $533(15.24)$ & $222(13.43)$ & $222 / 533(41.65)$ \\
\hline Car & $536(15.33)$ & $257(15.55)$ & $257 / 536(47.94)$ \\
\hline Others & $36(1.02)$ & $17(1.02)$ & $17 / 36(47.22)$ \\
\hline Patient's role on the road ${ }^{\mu}$ & $N=7226$ & $n=3550$ & $n / N(\%)$ \\
\hline Motorcyclist & $2,375(32.92)$ & $1,151(31.86)$ & $1,151 / 2,375(48.46)$ \\
\hline Bicyclist & $1,454(20.12)$ & $709(19.62)$ & $709 / 1,454(48.76)$ \\
\hline Pedestrian & $1,590(22.04)$ & $901(25.94)$ & $901 / 1,590(56.67)$ \\
\hline Bus/minibus occupant & $533(7.38)$ & $222(6.14)$ & $222 / 533(41.65)$ \\
\hline Car occupant & $536(7.43)$ & $271(7.11)$ & $271 / 536(50.56)$ \\
\hline Others & $738(10.23)$ & $301(8.33)$ & $301 / 738(40.79)$ \\
\hline RTC site ň $^{\text {na }}$ & $N=7092$ & $n=3411$ & $n / N(\%)$ \\
\hline Urban site & $4,873(65.71)$ & $2,372(65.65)$ & $2,372 / 4,873(48.68)$ \\
\hline Rural site & $2,167(29.22)$ & $1,009(27.93)$ & $1,009 / 2,167(46.56)$ \\
\hline Unknown & $52(0.73)$ & $30(0.88)$ & $30 / 52(57.69)$ \\
\hline \multicolumn{4}{|l|}{ Use of safety equipment** } \\
\hline Seat belt & $96 / 553(17.36)$ & $46 / 266(17.29)$ & $46 / 96(47.92)$ \\
\hline Helmet & $889 / 2,375(37.43)$ & $410 / 1,151(35.62)$ & $410 / 889(46.12)$ \\
\hline Alcohol status $^{\mathrm{H}}$ & $N=4,013$ & $n=2,106$ & $n / N(\%)$ \\
\hline None reported & $1,182(29.45)$ & $524(24.88)$ & $524 / 1,182(44.33)$ \\
\hline Confirmed use & $47(1.17)$ & $30(1.42)$ & $30 / 47(63.82)$ \\
\hline Unknown or missing & $2,784(69.37)$ & $1,552(73.69)$ & $1,552 / 2,784(55.75)$ \\
\hline Time of accident & $N=7251$ & $n=3555$ & $n / N(\%)$ \\
\hline 0000-0559 hrs & $651(8.78)$ & $340(9.41)$ & $340 / 651(52.22)$ \\
\hline $0600-1159 \mathrm{hrs}$ & $2,639(35.59)$ & $1,175(32.53)$ & $1,175 / 2,639(44.52)$ \\
\hline $1200-1759 \mathrm{hrs}$ & $2,017(27.20)$ & $984(27.23)$ & 984/2, 017 (48.79) \\
\hline $1800-2359 \mathrm{hrs}$ & $1,944(26.21)$ & $1,056(29.23)$ & $1,056 / 1,944(54.32)$ \\
\hline${\text { Duration of } \operatorname{arrival}^{\varphi}}^{\varphi}$ & $N=5,985$ & $n=2,762$ & $n / N(\%)$ \\
\hline$<30$ minutes & $750(12.53)$ & $298(10.79)$ & $298 / 750(39.73)$ \\
\hline 30-60 minutes & $1,787(29.86)$ & $804(29.11)$ & $804 / 1,787$ (44.99) \\
\hline $60-120$ minutes & $1,781(29.76)$ & $822(29.76)$ & $822 / 1,781(46.15)$ \\
\hline $120-180$ minutes & $773(12.92)$ & $400(14.48)$ & $400 / 773(51.75)$ \\
\hline$>180$ minutes & $894(14.94)$ & $438(15.86)$ & 438/894 (48.99) \\
\hline
\end{tabular}

Most patients presented directly from the scene of the crash, with almost half of them using motorized (two- or three-wheelers) as means of transport to the facilities. Formal emergency transports such as ambulances were rarely used even in serious cases. Consequently, most patients arrived at the health facilities more than one hour after the injury incidents, which is high compared to what has been observed in other studies in some similar settings and in HICs [22]. As shown in previous studies, lack of formal prehospital care is one of the major challenges in improving outcomes of immediate postcrash care [23-25] and might have an impact on both morbidity and mortality.

In emergency care settings, the initial triage score of injury victims is known to be associated with injury severity as well as a clinical outcome [26]. Over $90 \%$ of patients were triaged at priority or emergency triage level, requiring immediate life-saving interventions in the EUs to save lives and/or reduce the likelihood of developing lifelong disabilities. These findings suggest the future need to assess the association of triage scale with severity or clinical outcomes and to further evaluate, design, and provide dedicated training on triage processes to ensure proper prioritization of care and patient transfer.

Similar to previously published studies $[27,28]$, head injuries accounted for the largest category of serious injuries highlighting the resource-intensive nature of these injuries. In Tanzania, there is a scarcity of advanced neurosurgical care, with only one tertiary-level trauma care center that is fully equipped with resources to provide advanced neurosurgical care to these patients [29]. We believe a study of long-term outcomes among these patients will help quantify the actual burden and impact of head injuries to these patients and help develop a clear protocol for admission, discharge, and referral to optimize outcomes. 
TABle 3: ICD-10 diagnosis and final EU disposition.

\begin{tabular}{|c|c|c|c|c|c|}
\hline ICD-10 diagnosis* $^{\text {All patients }}{ }^{\mathrm{n}}$ & $\begin{array}{l}\text { Discharged } \\
N=7,128\end{array}$ & $\begin{array}{c}\text { Nondischarged }^{\mu} \\
3,613 \\
\end{array}$ & $\begin{array}{c}\text { Proportion of } \\
\text { nondischarged } \\
\quad 3,515 \\
\end{array}$ & $p$ value $e^{u ̛ p}$ & $n / N(\%)$ \\
\hline Multiple superficial injuries, unspecified & $2,535(35.6)$ & $1,698(47.0)$ & $837(23.8)$ & $\begin{array}{c}837 / 2,535 \\
(33.0)\end{array}$ & $p<0.0001$ \\
\hline Open wound of unspecified body region & $1,899(26.6)$ & $1,354(37.5)$ & $545(15.5)$ & $\begin{array}{c}545 / 1,899 \\
(28.7)\end{array}$ & $p<0.0001$ \\
\hline Intracranial injury & $1,110(15.6)$ & $133(3.7)$ & $977(27.8)$ & $\begin{array}{c}977 / 1,110 \\
(88.0)\end{array}$ & $p<0.0001$ \\
\hline Fracture of lower leg, including ankle & $898(12.6)$ & $233(6.4)$ & $665(18.9)$ & $\begin{array}{c}665 / 898 \\
(74.1)\end{array}$ & $p<0.0001$ \\
\hline Fracture of femur & $466(6.5)$ & $13(0.4)$ & $453(12.9)$ & $\begin{array}{c}453 / 466 \\
(97.2)\end{array}$ & $p<0.0001$ \\
\hline Fracture of forearm & $251(3.5)$ & $94(2.6)$ & $157(4.5)$ & $\begin{array}{c}157 / 251 \\
(62.5)\end{array}$ & $p<0.0001$ \\
\hline Fracture of shoulder and upper arm & $230(3.2)$ & $62(1.7)$ & $168(4.8)$ & $\begin{array}{c}168 / 230 \\
(73.0)\end{array}$ & $p<0.0001$ \\
\hline Unspecified injury of thorax & $170(2.4)$ & $39(1.1)$ & $131(3.7)$ & $\begin{array}{c}131 / 170 \\
(77.1)\end{array}$ & $p<0.0001$ \\
\hline $\begin{array}{l}\text { Sprain and strain of other and unspecified parts of } \\
\text { foot }\end{array}$ & $115(1.6)$ & $95(2.6)$ & $20(0.6)$ & 20/115 (17.4) & $p<0.0001$ \\
\hline Fracture of unspecified body region & $104(1.5)$ & $17(0.5)$ & $87(2.5)$ & $87 / 104(83.7)$ & $p<0.0001$ \\
\hline Fracture of skull and facial bones & $84(1.2)$ & $19(0.5)$ & $65(1.8)$ & $65 / 84(77.4)$ & $p<0.0001$ \\
\hline $\begin{array}{l}\text { Dislocation, sprain, and strain of joints and } \\
\text { ligaments of shoulder girdle }\end{array}$ & $79(1.1)$ & $36(1.0)$ & $43(1.2)$ & $43 / 79(54.4)$ & $p=0.4180$ \\
\hline $\begin{array}{l}\text { Dislocation, sprain, and strain of joints and } \\
\text { ligaments of knee }\end{array}$ & $79(1.1)$ & $21(0.6)$ & $58(1.7)$ & $58 / 79(73.4)$ & $p<0.0001$ \\
\hline Fracture at wrist and hand level & $79(1.1)$ & $41(1.1)$ & $38(1.1)$ & $38 / 79(48.1)$ & $p=1.0$ \\
\hline Fracture of lower leg, including ankle & $64(0.9)$ & $20(0.6)$ & $44(1.3)$ & $44 / 64(68.8)$ & $p=0.0023$ \\
\hline Open wounds of head, neck, and trunk & $62(0.9)$ & $32(0.9)$ & $30(0.9)$ & $30 / 62(48.4)$ & $p=1.0$ \\
\hline Dislocation, unspecified & $58(0.8)$ & $17(0.5)$ & $41(1.2)$ & $41 / 58(70.7)$ & $p=0.0012$ \\
\hline Injury, unspecified & $49(0.7)$ & $25(0.7)$ & $24(0.7)$ & $24 / 49(48.9)$ & $p=1.0$ \\
\hline Fracture of lumbar spine and pelvis & $44(0.6)$ & $3(0.1)$ & $41(1.2)$ & $41 / 44(93.2)$ & $p<0.0001$ \\
\hline $\begin{array}{l}\text { Dislocation, sprain, and strain of joints and } \\
\text { ligaments at ankle and foot level }\end{array}$ & $44(0.6)$ & $18(0.5)$ & $26(0.7)$ & $26 / 44(59.1)$ & $p=0.2738$ \\
\hline
\end{tabular}

TABLE 4: Final EU disposition by patient's role.

\begin{tabular}{|c|c|c|c|c|c|}
\hline Disposition & $\begin{array}{c}\text { Overall } \\
n=7416 \\
n(\%)\end{array}$ & $\begin{array}{c}\text { Pedestrian } \\
n=1590 \\
n(\%)\end{array}$ & $\begin{array}{c}\text { Motorcyclist } \\
n=2375 \\
n(\%)\end{array}$ & $\begin{array}{c}\text { Cyclist } \\
n=1454 \\
n(\%)\end{array}$ & $\begin{array}{c}\text { Car occupant } \\
n=536 \\
n(\%)\end{array}$ \\
\hline Admitted to hospital* & $2,675(36.07)$ & $766(48.20)$ & $859(36.25)$ & $477(32.97)$ & $163(30.60)$ \\
\hline Discharged home & $3,708(50.00)$ & $669(42.16)$ & $1,214(51.22)$ & $731(50.52)$ & $259(48.87)$ \\
\hline OT admission & $80(1.08)$ & $18(1.13)$ & $31(1.31)$ & $11(0.76)$ & $6(1.13 \%)$ \\
\hline Referred & $785(10.59)$ & $105(6.60)$ & $243(10.25)$ & $202(13.96)$ & $78(14.72)$ \\
\hline Died $^{\text {ń }}$ & $144(1.94)$ & $31(1.95)$ & $26(1.09)$ & $30(2.06)$ & $27(5.03)$ \\
\hline Unknown & $24(1.28 \%)$ & $1(0.06)$ & $2(0.42)$ & $3(0.96)$ & $3(3.73)$ \\
\hline
\end{tabular}

*Include wards and ICU admission. ${ }^{\check{n}}$ Include $73(0.98 \%)$ deaths in the EU and $71(0.96 \%)$ in transit or on the scene of the crash.

4.1. Limitations. This study was conducted on a purposefully selected sample of health facilities located within $2 \mathrm{~km}$ of busy highways in Tanzania and may not necessarily reflect the actual burden of RTC across other regions. However, the diverse nature of these health facilities (ranging from dispensary level to regional hospital level) provided an opportunity to understand the burden at different levels of care across the country. The data collection was also affected by 


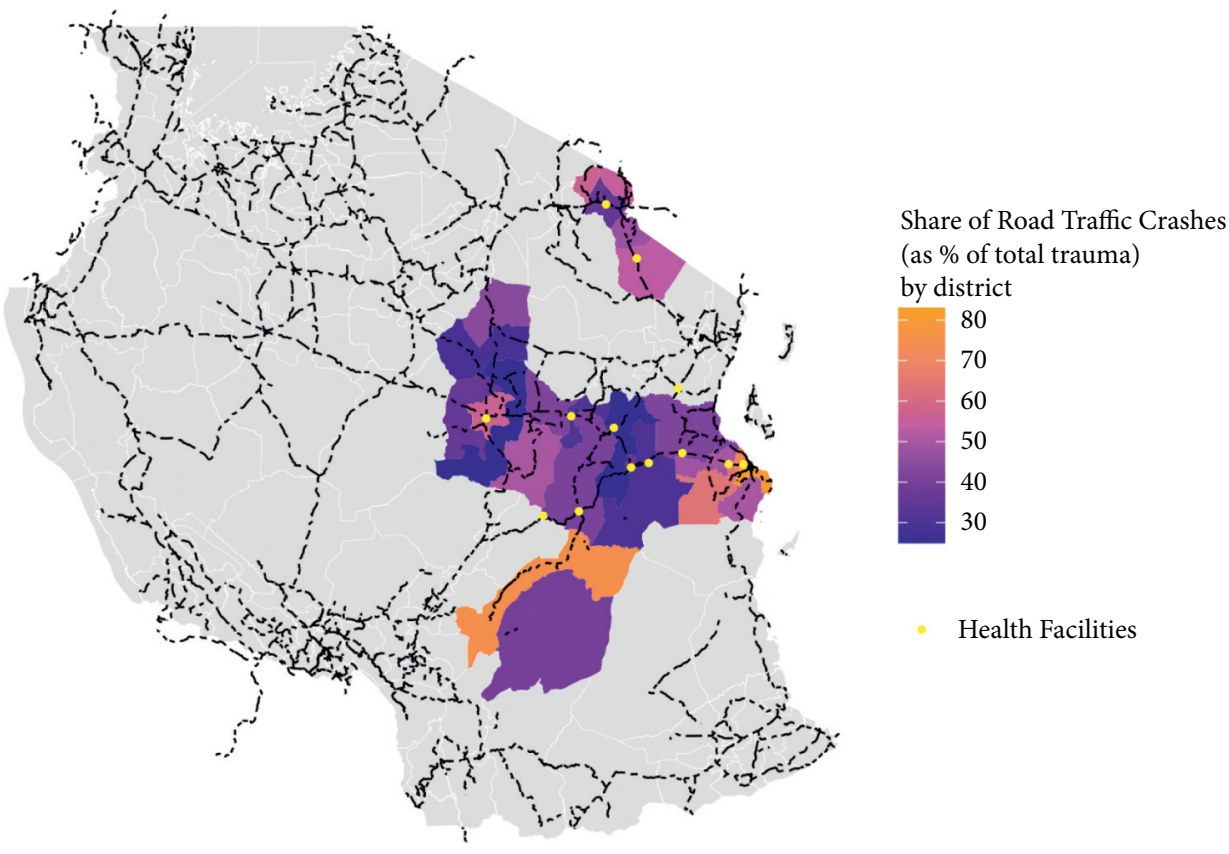

Figure 2: Heat map of accident hotspots*. Note: This map shows road traffic crashes as a percentage share of total trauma in the trauma registry at the district level. The colored region represents 30 districts surrounding the facilities (seen in yellow dots), which were recorded in the trauma registry. Lighter shade represents a higher share of road traffic crashes recorded in a given district. The gray portion refers to other districts in Tanzania, which were not recorded in the trauma registry. The dashed black lines represent the highways and other primary roads in Tanzania.

COVID-19 in different ways. First, the partial lockdown in the early months of COVID-19 in Tanzania might have led to a decline in the number of accidents. Nevertheless, the partial lockdown in Tanzania was only for a brief period of time (approximately 10 weeks), and we do not find a sudden drop in RTI cases, instead of finding consistency in the number of cases across months. Second, the COVID-19 pandemic led to a withdrawal of RAs from the sites of data collection to reduce their risk of being exposed; this affected the quality and quantity of data, as clinicians were not able to enter all the data without the assistance of the RAs. Third, due to the COVID-19 pandemic, there was a deviation of cases that were dead on arrival to the mortuary without passing through the EUs, and this practice affected the observations for death at the crash scene or in transit to EUs, and it might have resulted in underestimates of the total deaths.

\section{Conclusion}

RTCs are the main cause of trauma in Tanzania affecting mostly male, economically productive age groups, and they result in severe injuries in almost half of victims. Motorcyclists remain the most commonly affected group; in alignment with several prior studies, however, pedestrians and cyclists also constituted a substantial proportion. The impact of lack of formal prehospital care was demonstrated by utilization of private means of transport and delays in RTIs patients' arrival at the health facility. These findings demonstrate the burden of RTCs as a first-order public health concern in Tanzania and signify the need for targeted policy efforts towards reducing RTCs and improving postinjury care at all levels.

\section{Data Availability}

The data sets used and/or analyzed during the current study are available on request from principal administrators.

\section{Ethical Approval}

The study protocol was reviewed and approved by the National Health Research Ethics Review Committee (NatREC). The IRB approved a waiver of patient consent. The permission to publish was obtained from the National Health Research Ethics Review Committee (NatREC).

\section{Disclosure}

The findings, interpretations, and conclusions expressed in this paper do not necessarily reflect the views of the World Bank, the Executive Directors of the World Bank, or the governments whom they represent. The World Bank does not guarantee the accuracy of the data included in this work.

\section{Conflicts of Interest}

The authors declare that there are no conflicts of interest.

\section{Authors' Contributions}

HRS and JAM contributed to the conception and design of the study; acquired, analzsed, and interpreted the data; and drafted the manuscript. SM contributed to the conception and design of the data collection, data acquisition, data monitoring, data cleaning, analysis, interpretation, and 
fundraising. KC contributed to the conception and design of the data collection and fundraising and assisted with data interpretation. SK contributed to the conception and design of the data collection, data monitoring, and fundraising. MM contributed to data cleaning and data analysis. All authors read, revised, and approved the final manuscript.

\section{Acknowledgments}

The authors would like to thank the Ministry of Health, Community Development, Gender, Elderly and Children (MoHCDGEC), President's Office Regional Administration and Local Government (PORALG), Ministry of Works, Transport and Communications, and the Ministry of Home Affairs (traffic police division) for their support in the process of setting up and data collection of this project. The authors thank Ms. Chiku Simbano, Mr. Ramadhani Mashoka, Ms. Kriti Malhotra, Ms. Doreen Shango, and Ms. Jonna Margaret Bertfelt, as well as the incharge of each health facility, Trauma Data Coordinators, and Research Assistants for their research assistance in the collection of this data. The authors would also like to thank the World Bank Country Office in Tanzania, especially the Health sector team members, including Inaam Ul Haq, Peter Okwero, Mariam Ally, and Chiho Suzuki, for their support with this project, as well as the World Bank Operations project team leads, Gylfi Palsson and Dominic S. Haazen. This project was funded by the UK Aid Foreign Commonwealth \& Development Office (FCDO) of the United Kingdom Government, including through the ieConnect for Impact Program as well as through support from the Research Support Budget in the Development Economics VicePresidency of the World Bank.

\section{References}

[1] WHO, Global Status Report on Road Safety 2018, World Health Organization, Geneva, Switzerland, 2018.

[2] World Bank, The State of Emergency Medical Services in SubSaharan Africa, World Bank, Washington, DC, USA, 2021, https://openknowledge.worldbank.org/handle/10986/35175.

[3] H. R. Sawe, J. A. Mfinanga, K. R. Mbaya et al., "Trauma burden in Tanzania: a one-day survey of all district and regional public hospitals," BMC Emergency Medicine, vol. 17, no. 1, p. 30, 2017.

[4] R. Boniface, L. Museru, O. Kiloloma, and V. Munthali, "Factors associated with road traffic injuries in Tanzania," The Pan African Medical Journal, vol. 23, p. 46, 2016.

[5] M. Mwandri, T. C. Hardcastle, H. Sawe et al., "Trauma burden, patient demographics and care-process in major hospitals in Tanzania: a needs assessment for improving healthcare resource management," African Journal of Emergency Medicine, vol. 10, no. 3, pp. 111-117, 2020.

[6] K. Kuzma, A. G. Lim, B. Kepha, N. E. Nalitolela, and T. A. Reynolds, “The Tanzanian trauma patients' prehospital experience: a qualitative interview-based study," BMJ Open, vol. 5, no. 4, Article ID e006921, 2015.

[7] P. M. Koka, H. R. Sawe, K. R. Mbaya et al., "Disaster preparedness and response capacity of regional hospitals in
Tanzania: a descriptive cross-sectional study," BMC Health Services Research, vol. 18, no. 1, p. 835, 2018.

[8] P. L. Chalya, J. B. Mabula, R. M. Dass et al., "Injury characteristics and outcome of road traffic crash victims at Bugando medical centre in Northwestern Tanzania," Journal of Trauma Management and Outcomes, vol. 6, no. 1, p. 1, 2012.

[9] J. Whitaker, N. O’Donohoe, M. Denning et al., “Assessing trauma care systems in low-income and middle-income countries: a systematic review and evidence synthesis mapping the three delays framework to injury health system assessments," BMJ Global Health, vol. 6, no. 5, Article ID e004324, 2021.

[10] The World Bank, Southern Africa Trade and Transport Facilitation Project, World Bank Projects and Operations, World Bank, Washington, DC, USA, 2013, https://projects. worldbank.org/P120370/southern-africa-trade-transportfacilitation-project?lang=en\&tab=details.

[11] The World Bank, The World Bank in Tanzania, World Bank, Washington, DC, USA, 2020, https://www.worldbank.org/en/ country/tanzania.

[12] National Bureau of Statistics, "Tanzania national population projections," 2021, https://www.nbs.go.tz.

[13] B. A. Nicks, H. R. Sawe, A. M. Juma, and T. A. Reynolds, "The state of emergency medicine in the United Republic of Tanzania," African Journal of Emergency Medicine, vol. 2, no. 3, pp. 97-102, 2012.

[14] H. R. Sawe, T. A. Reynolds, E. J. Weber, J. A. Mfinanga, T. J. Coats, and L. A. Wallis, "Development and pilot implementation of a standardised trauma documentation form to inform a national trauma registry in a low-resource setting: lessons from Tanzania," BMJ Open, vol. 10, no. 10, Article ID e038022, 2020.

[15] WHO, "WHO standardized clinical form," WHO Standardized Clinical Form, World Bank, Washington, DC, USA, 2020, https://www.who.int/publications/i/item/who-standardizedclinical-form.

[16] O. C. Kobusingye and R. R. Lett, "Hospital-based trauma registries in Uganda," The Journal of Trauma, Injury, Infection, and Critical Care, vol. 48, no. 3, pp. 498-502, 2000.

[17] M. R. Bambach and R. J. Mitchell, "The rising burden of serious thoracic trauma sustained by motorcyclists in road traffic crashes," Accident Analysis and Prevention, vol. 62, pp. $248-258,2014$.

[18] G. Craft, T. Van Bui, M. Sidik et al., "A comprehensive approach to motorcycle-related head injury prevention: experiences from the field in Vietnam, Cambodia, and Uganda," International Journal of Environmental Research and Public Health, vol. 14, no. 12, Article ID E1486, 2017.

[19] L. Chokotho, K. Croke, M. Mohammed, J. Bertfelt, S. Karpe, and S. Milusheva, "Epidemiology of adult trauma injuries in Malawi: results from a multi-site trauma registry," Submiss, 2021.

[20] V. Gitelman, D. Balasha, R. Carmel, L. Hendel, and F. Pesahov, "Characterization of pedestrian accidents and an examination of infrastructure measures to improve pedestrian safety in Israel," Accident Analysis and Prevention, vol. 44, no. 1, pp. 63-73, 2012.

[21] D. Khorasani-Zavareh, R. Mohammadi, H. R. Khankeh, L. Laflamme, A. Bikmoradi, and B. J. Haglund, "The requirements and challenges in preventing of road traffic injury in Iran: a qualitative study," BMC Public Health, vol. 9, no. 1, p. 486, 2009.

[22] M. Bigdeli, D. Khorasani-Zavareh, and R. Mohammadi, "Prehospital care time intervals among victims of road traffic 
injuries in Iran. A cross-sectional study," BMC Public Health, vol. 10, no. 1, p. 406, 2010.

[23] G. Tansley, N. Schuurman, M. Bowes et al., "Effect of predicted travel time to trauma care on mortality in major trauma patients in Nova Scotia," Canadian Journal of Surgery, vol. 62, no. 2, pp. 123-130, 2019.

[24] C. Mock, M. Joshipura, C. Arreola-Risa, and R. Quansah, “An estimate of the number of lives that could be saved through improvements in trauma care globally," World Journal of Surgery, vol. 36, no. 5, pp. 959-963, 2012.

[25] C. Mock, "Injury in the developing world," Western Journal of Medicine, vol. 175, no. 6, pp. 372-374, 2001.

[26] A. Cassignol, J. Marmin, J. Cotte et al., "Correlation between field triage criteria and the injury severity score of trauma patients in a French inclusive regional trauma system," Scandinavian Journal of Trauma, Resuscitation and Emergency Medicine, vol. 27, no. 1, p. 71, 2019.

[27] P. L. Chalya, E. S. Kanumba, J. B. Mabula, G. Giiti, and J. M. Gilyoma, "Aetiological spectrum, injury characteristics and treatment outcome of head injury patients at Bugando Medical Centre in north-western Tanzania," Tanzania Journal of Health Research, vol. 13, no. 1, pp. 74-81, 2011.

[28] H. R. Sawe, L. A. Wallis, E. J. Weber, J. A. Mfinanga, T. J. Coats, and T. A. Reynolds, "The burden of trauma in Tanzania: analysis of prospective trauma registry data at regional hospitals in Tanzania," Injury, vol. 51, no. 12, pp. 2938-2945, 2020.

[29] D. R. Ormond, J. Kahamba, K. O. Lillehei, and N. Rutabasibwa, "Overcoming barriers to neurosurgical training in Tanzania: international exchange, curriculum development, and novel methods of resource utilization and subspecialty development," Neurosurgical Focus, vol. 45, no. 4, p. E6, 2018. 